\title{
The effect of timing electrical stimulation to robotic-assisted stepping on neuromuscular activity and associated kinematics
}

\author{
Sina Askari, MS; ${ }^{1}$ TeKang Chao; ${ }^{1}$ Ray D. de Leon, PhD; ${ }^{2}$ Deborah S. Won, PhD $^{\mathbf{1}^{*}}$ \\ ${ }^{1}$ Department of Electrical Engineering and ${ }^{2}$ School of Kinesiology and Nutritional Science, California State Univer- \\ sity, Los Angeles, CA
}

\begin{abstract}
Results of previous studies raise the question of how timing neuromuscular functional electrical stimulation (FES) to limb movements during stepping might alter neuromuscular control differently than patterned stimulation alone. We have developed a prototype FES system for a rodent model of spinal cord injury (SCI) that times FES to robotic treadmill training (RTT). In this study, one group of rats $(n=6)$ was trained with our FES+RTT system and received stimulation of the ankle flexor (tibialis anterior [TA]) muscle timed according to robot-controlled hind-limb position (FES+RTT group); a second group $(n=5)$ received a similarly patterned stimulation, randomly timed with respect to the rats' hind-limb movements, while they were in their cages (randomly timed stimulation [RS] group). After 4 wk of training, we tested treadmill stepping ability and compared kinematic measures of hind-limb movement and electromyography (EMG) activity in the TA. The FES+RTT group stepped faster and exhibited TA EMG profiles that better matched the applied stimulation profile during training than the RS group. The shape of the EMG profile was assessed by "gamma," a measure that quantified the concentration of EMG activity during the early swing phase of the gait cycle. This gamma measure was $112 \%$ higher for the FES+RTT group than for the RS group. The FES+RTT group exhibited burst-to-step latencies that were $41 \%$ shorter and correspondingly exhibited a greater tendency to perform ankle flexion movements during stepping than the RS group, as measured by the percentage of time the hind limb was either dragging or in withdrawal. The results from this study support the hypothesis that locomotor training consisting of FES timed to hind-limb movement improves the activation of hind-limb muscle more so than RS alone. Our rodent FES+RTT system can serve as a tool to help further develop this combined therapy to target appropriate neurophysiological changes for locomotor control.
\end{abstract}

Key words: activity-dependent plasticity, electromyography, functional electrical stimulation, locomotion, neuromuscular electrical stimulation, rehabilitation, robotic treadmill training, rodent model, spinal cord injury, spinal plasticity, step kinematics.

\section{INTRODUCTION}

Neuromuscular functional electrical stimulation (FES) has been used to strengthen muscles that are weakened by neurological damage [1-10]. It is also typically used to artificially replace muscle activation that is missing due to spinal cord injury (SCI) and other neurological damage [11-18]. To assist walking, FES is applied to nerves that innervate the leg muscles so that the muscles are artificially activated at predetermined times when the activation would have been expected to occur in a normal

\footnotetext{
Abbreviations: $\mathrm{CDF}=$ cumulative distribution function, $\mathrm{CPN}=$ common peroneal nerve, EMG = electromyography, FES = functional electrical stimulation, $\mathrm{NIH}=$ National Institutes of Health, $\mathrm{PC}=$ paw contact, $\mathrm{RS}=$ randomly timed stimulation, $\mathrm{RTT}=$ robotic treadmill training, $\mathrm{SCI}=$ spinal cord injury, $\mathrm{SD}=$ standard deviation, $\mathrm{TA}=$ tibialis anterior, $\mathrm{TO}=$ toe-off, $\mathrm{WSTT}=$ weight-supported treadmill training.

*Address all correspondence to Deborah S. Won, PhD; 5151 State University Dr, Department of Electrical Engineering, California State University, Los Angeles, CA 90032; 323-343-5908; fax: 323-343-4597.
}

Email: dwon@calstatela.edu

http://dx.doi.org/10.1682/JRRD.2012.06.0111 
gait cycle [10-11,14,19-20]. For these applications, FES was designed to directly stimulate peripheral nerves to cause muscle contractions that lead to the muscle conditioning and functional motor output, which have given FES its value as a medical technology. These more immediate effects are referred to as "orthotic" effects [21].

The lasting improvements, or "therapeutic" effects [21], observed particularly in walking after a course of FES therapy $[8,12,22-23]$ raise the question of whether FES may also have an effect on the neural circuitry that controls stepping. Long-term application of FES in combination with weight-supported treadmill training (WSTT) has been shown to improve walking in individuals with SCI $[8,24-26]$. More recent findings suggest that the therapeutic effect of FES may be mediated by a strengthening of corticospinal connections to ankle dorsiflexor muscles such as the tibialis anterior (TA) $[21,27]$. There is evidence that repetitive FES alone (i.e., stimulation that is not paired with movement but applied while subjects were seated) can modulate corticospinal circuits controlling ankle dorsiflexion [28-31]. For example, motor-evoked potentials in the TA were increased by $30 \mathrm{~min}$ of repetitive stimulation of the common peroneal nerve (CPN) in subjects with SCI [29]. Stimulating the CPN during voluntary ankle flexion further increases motor cortical excitability [32]. These findings suggested that FES of the CPN, with or without limb movements, enhanced corticospinal circuits controlling limb muscles. However, whether and how timing FES with limb movements enhances the effects of the patterned but randomly timed stimulation (RS) at the motoneuron and behavioral level have not been determined to the best of our knowledge.

We have been developing an FES therapy in a rodent model of SCI that attempts to enhance spinal plasticity by appropriately timing the FES during treadmill training. Our FES system takes advantage of the capabilities of a robotic treadmill training (RTT) device developed to assist WSTT; namely, the capability to drive leg movements through consistent trajectory patterns during stepping [33-34] and to continuously sense the hind-limb ankle position [35]. Recently, Jung et al. demonstrated successful implementation of adaptive FES control in spinally contused rats [36]. Stimulation was delivered in a cyclical pattern to hip muscles while the rats were suspended such that their limbs moved freely and feedback control was applied to produce a desired hip angle trajectory as expected during locomotion. The resulting improvement in interlimb coordination lends support to the notion that patterned FES associated with limb move- ments could be used to enhance locomotor recovery after SCI [36-37].

However, our FES+RTT system was not engineered with as much intent to produce a certain gait trajectory during training; rather, the primary goal of our design was to time FES of the TA to coincide with afferent feedback that was naturally generated during WSTT in an attempt to reinforce this afferent activity. A variety of afferent inputs, such as load receptors and proprioceptors, access spinal locomotor pattern generators and have been shown to drive and reset locomotor output [38-40]. The ability to modulate spinal plasticity, and resulting functional recovery, by hind-limb afferent stimuli has also been demonstrated in a number of previous studies [41-43]. Recent evidence that FES of cutaneous afferent pathways is effective in modulating the generation of stepping in cats and humans with SCI [44-45] could indicate that applied stimulation may enhance afferent modulation of spinal circuitry.

Here, we compared effects of FES timed to hind-limb movements during RTT (FES+RTT) versus that same patterned stimulation alone (RS) in spinally contused rats; since the latter group received stimulation that was not coordinated with their hind-limb movements, we refer to this group as the RS group. Our overall hypothesis was that FES appropriately timed to robot-controlled stepping would facilitate plasticity within the spinal cord circuitry involved in walking more so than patterned stimulation alone. To test this hypothesis, we compared hind-limb kinematics and electromyography (EMG) patterns between the FES+RTT and RS groups. This study also provides a foundation for further studying underlying mechanisms of a combined FES and WSTT therapy in a rodent model and for optimizing this FES therapy to enhance neuromuscular control of stepping and achieve more than muscle strengthening or immediate muscle facilitation.

\section{MATERIALS AND METHODS}

The general design of the study is described here and details are found next. Electrodes were surgically implanted in the TA muscle of 14 adult female SpragueDawley rats (250-300 g), followed by a severe spinal cord contusion 1 wk later. Rats were divided into two training groups. In the FES+RTT group, FES of the TA was integrated with RTT to allow precise coordination of FES with robot-controlled stepping patterns. In the RS 
group, FES of the TA occurred while the rats were in their cages. Tests of independent stepping were performed after 4 wk of training.

\section{Surgical Procedures}

All surgical procedures were performed aseptically and with isoflurane anesthesia. Intramuscular bipolar electrodes were implanted in the TA of both hind limbs using methods similar to those in Lee et al. [46]. Microstimulation was applied during surgery to elicit muscle twitch activity to ensure appropriate placement of the electrodes. The electrode assemblies consisted of Tefloncoated multistranded stainless steel wire (Cooner Wire Company; Chatsworth, California) connected to the pins of a 9-pin plastic connector (Wirepro; Glenview, Illinois) that was cemented to the skull.

All rats were contused at the midthoracic (T9) level approximately $1 \mathrm{wk}$ after the electrode implant surgery (for details, see Heng and de Leon [47]). After the skin over the vertebral column was shaved and cleaned, the spinal cord at the midthoracic vertebral level was exposed. A force impactor (Precision Systems and Instrumentation; Lexington, Kentucky) delivered a 250 kdyn downward force directly onto the spinal cord in order to induce a severe spinal contusion injury. After all surgical procedures, the rats were allowed to recover in a warm incubator and returned to their cages.

\section{Stimulation}

The stimulation procedures are already described in Chao et al. [48] but are briefly outlined again here. Biphasic square wave $100 \mu$ s pulses were delivered at 70 pulses per second while the rat was performing RTT (Figure 1). The rat was suspended by a harness to support 85 percent of its body weight, while its hind limbs were guided by robot-controlled attachments. A desired trajectory was programmed into the robot (Figure 2), and a proportional-integral-derivative controller was employed to keep the rat's hind limb within a small window around the desired trajectory. The robot directly controls only the ankle joint's trajectory, but as a result of the mechanical linkage with other joints and the shape of the programmed trajectory, the knee and hip joints are also influenced by the robotic forces.

The stimulator (S88x, Grass Technologies; Warwick, Rhode Island) was programmed to turn on from toe-off (TO) until the rat lifted its ankle to peak swing position, which we refer to as the "upswing" phase of the gait

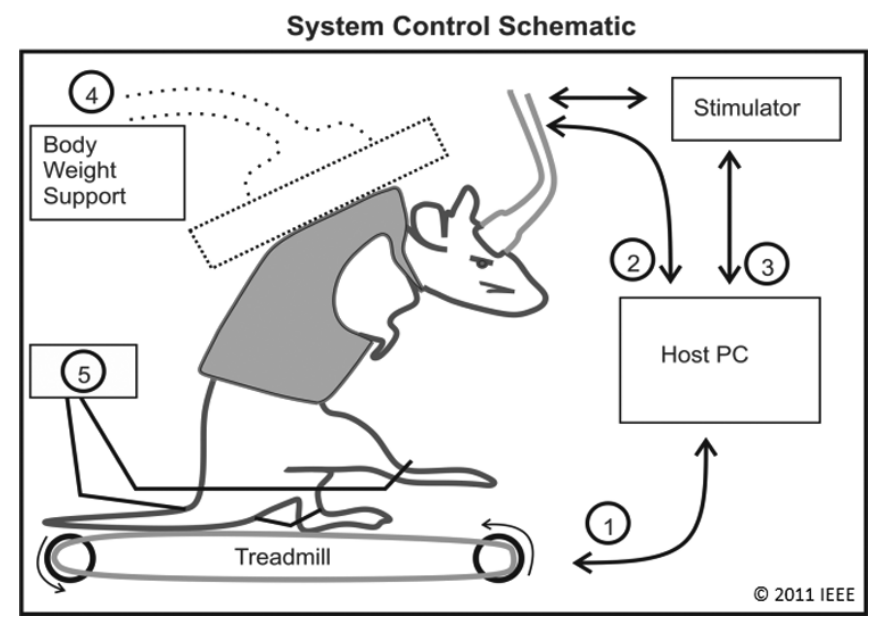

Figure 1.

Schematic of integrated functional electrical stimulation + robotic treadmill training (FES+RTT) system. Control system was implemented in LabWindows/CVI and LabView-based programs (National Instruments Corporation; Austin, Texas), which was responsible for controlling (1) treadmill speed, (2) acquisition of electromyography from tibialis anterior muscles via head-mounted connector, (3) delivery of stimulation at desired times and specified parameter settings, (4) appropriate bodyweight support, and (5) proportional-integral-derivativecontrolled force to hind limbs via robotic arms attached to rat's ankles as well as recording actual hind-limb position sensed from optical encoders. Robot moves rat's ankles but also indirectly causes knee and hip to move approximately along trajectory suitable for stepping. (Reprinted with permission from Askari S, Chao T, Conn L, Partida E, Lazzaretto T, See PA, Chow C, de Leon RD, Won DS. Effect of functional electrical stimulation (FES) combined with robotically assisted treadmill training on the EMG profile. Conf Proc IEEE Eng Med Biol Soc. 2011;2011:3043-46. [PMID:22254981])

cycle; this period is when ankle flexion is most needed to help the paw clear the ground during stepping, analogous to preventing foot drop in patients. Figure 3(b) shows the pattern of stimulation for the FES+RTT group during training. The expected, or desired, pattern of stimulation during a few gait cycles of a training session is shown in the top line. The lower lines show the sensed $x$ and $y$ position recorded by the robot during training. For comparison, a brief recording of the position was made while robotic guidance was still on but FES was turned off during one training session of this particular animal. Turning FES on caused a disturbance in the $x$ and $y$ positions 

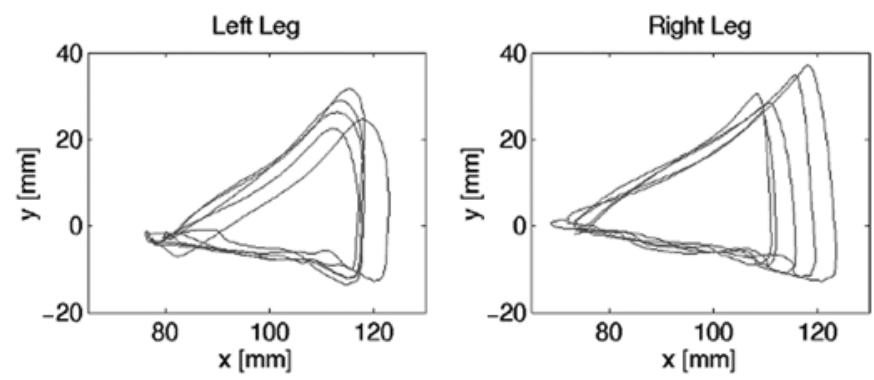

Figure 2.

During functional electrical stimulation and robotic treadmill training, robot guided left and right ankles, using feedback control, along illustrated trajectory, which consisted of a series of five gait cycles that were continuously repeated for full duration of training period.

(more specifically, moving the limb up and out); this disturbance is present in the position signal recorded while FES training was turned on (Figure 3(b)) but not in the position signal recorded while the treadmill training was briefly activated without FES (Figure 3(a)). Presently, only one stimulation pattern is programmed according to user input during device setup before each experimental training session, and timing is based on absolute position rather than estimated percent gait cycle.

Bipedal stepping is not the natural form of gait in rats. However, it has been commonly used in SCI models because it allows control of weight bearing on the hind limbs [49] and because the upright posture facilitates stepping performance [50]. The present study required that recording and stimulation were performed in the spinally contused rat during reliable plantar, weight-bearing stepping, which produces afferent activity, and this is best achieved with upright, bipedal locomotion [49-50].

\section{Training Protocol}

Half of the rats were assigned to the group that received the FES combined with RTT (FES+RTT) group; the other half was assigned to the control RS group, in which the patterned stimulation was applied at random times with respect to the animal's movements. The FES+RTT group was stimulated according to the programmed trajectory while performing RTT and at the same robotic control settings as used in Lee et al. [46]. According to the results of that study, high levels of robotic control that do not allow the subject as much flexibility in its step trajectory actually impede its recovery of stepping capabilities. The RTT control parameters were thus set to provide rigid assistance (feedback gains set high) so that, although the robot would guide the rat along step trajectories to which the FES could be timed, RTT itself would not provide any rehabilitative effects. This level of robotic assistance is also more comparable with that used in clinical practice.

Rats were trained $5 \mathrm{~d} / \mathrm{wk}$ for $4 \mathrm{wk}$, and at each training session, underwent FES+RTT therapy for 500 gait cycles at 85 percent body-weight support. The RS group received stimulation while in their cages. During RS training, a mechanical damper was placed between the robotic arms to simulate a rat's presence. Since there were no major resisting forces against the arm, the arms essentially moved in the desired trajectory; meanwhile, the stimulator output was timed to this desired trajectory. FES was delivered for the same duration and with the same pattern as programmed during FES+RTT, but the RS group was not performing treadmill stepping, such that the stimulation was not timed to their movements. Thus, the RS group received the same patterned stimulation as a rat might have received during FES+RTT, but with random timing rather than synchronized to the upswing phase. Six of the seven rats in the FES+RTT group and five of the seven in the RS group completed training. Five rats in a previous study [46] underwent RTT only, and data from four of these rats were included in the kinematic and EMG burst analysis. The fifth rat lost its head plug implant partway through the study, so only step rate could be measured from video data of this rat.

\section{Data Acquisition}

EMG was recorded from a differential pair of electrodes in the TA muscle through an analog amplifier (P511, Grass Technologies) with a gain of 1,000 and bandpass filtering between 10 and 3,000 Hz. Hind-limb position was recorded directly from the robot and used to compute step kinematics. Ankle angle was computed from video images captured while the animal stepped on the treadmill. The toe, ankle, and knee were marked on the rat's right hind-limb, and the rat was videotaped during testing. Videos of all rats were digitized, marker coordinates were extracted, and joint angles computed using custom software written in MATLAB (MathWorks; Natick, Massachusetts).

\section{Kinematic and Electromyography Analysis}

Kinematic and EMG analyses were performed on data collected from the 11 rats (6 FES+RTT and 5 RS) that successfully completed the 4 wk of training. Step kinematics 
(a) Gait Cycle Without Stimulator

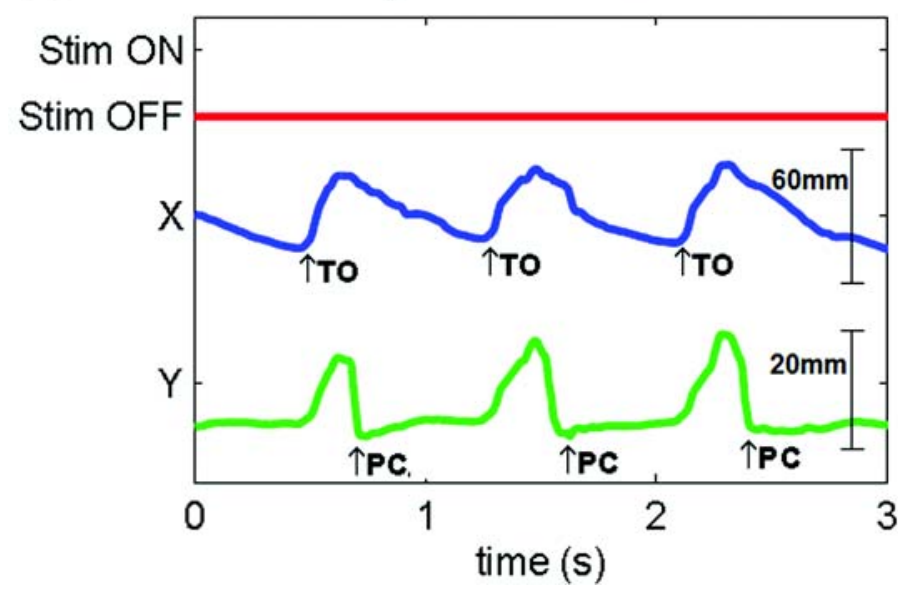

(b) Gait Cycle With Stimulator

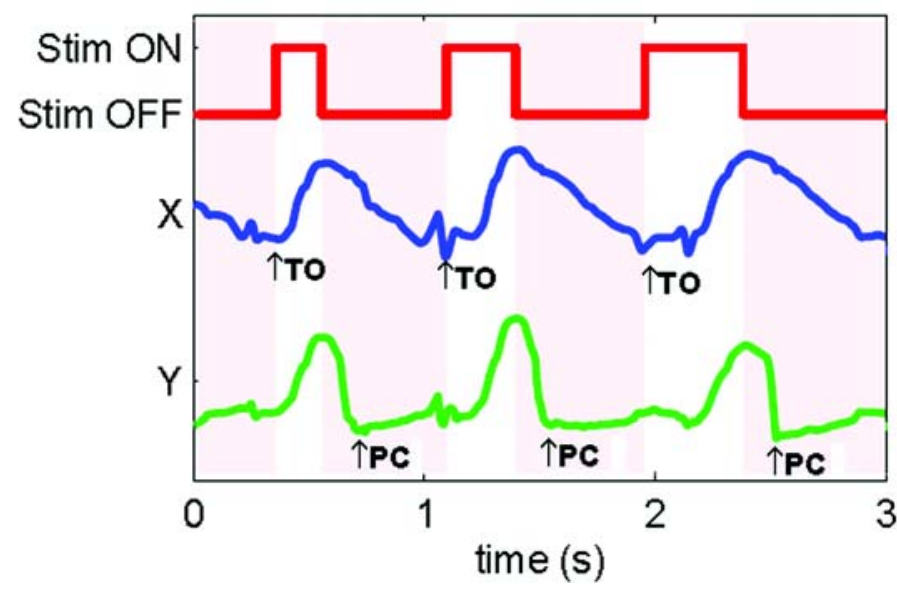

Figure 3.

Neuromuscular functional electrical stimulation (stim) was applied based on robot-controlled ankle position. Blue and green lines depict horizontal and vertical ankle position, respectively. (a) Stimulator is off and no stimulation is applied (red line). (b) Stimulator is on and stimulation is applied during forward upswing of ankle (white vertical bars). PC = paw contact, TO = toe-off.

were calculated from the acquired hind-limb position as described next. First, the start and end of each gait cycle were automatically detected from the position, recorded synchronously with EMG. Each step was defined as beginning at TO and ending at the next TO. The swing phase occurs during each gait cycle from TO to paw contact (PC). The upswing phase was defined as the first portion of the swing phase from TO to peak vertical $\left(y_{\text {peak }}\right)$ position. TO was determined by finding the time of the minimum horizontal, or $x$, position. $\mathrm{PC}$ was determined by finding the minimum $y$ after the maximum $x$. $y_{\text {peak }}$ is simply the time at which the maximum $y$ occurs. Step length was then defined as the $x$ displacement between TO and the next PC. Step height was defined as the maximum $y$ displacement during a gait cycle. Gait speed at final testing was also computed from the number of steps detected by the methods just described. Baseline gait speed was computed by visually detecting and counting steps from video data, since a data acquisition error resulted in the loss of most baseline data. However, steps could be counted from video recorded at baseline. Therefore, baseline gait speed is reported in the results, but no other baseline measurements were valid. The visual step count method from a couple of sample videos was compared against the automatic step detection and the results were comparable.

EMG profiles were created by averaging the EMG envelope during each step cycle across steps for each individual rat. The EMG envelope was found by fullwave rectifying the raw EMG and smoothing the rectified EMG with a moving average filter using a window length of $25 \mathrm{~ms}$. The concentration of EMG activity in the corresponding portion of the gait cycle during which FES was applied was also computed and defined as $\gamma$ (Equation (1)). In order to minimize intersubject variability [51-52], the average EMG profile for an individual rat was normalized to its maximum EMG during the gait cycle. Since FES was applied approximately during the initial 50 percent of the swing phase, $\gamma$ was defined as the proportion of total EMG activity during the gait cycle that occurred from 0 to 50 percent of the swing phase. In Equation (1), $s$ is the EMG profile of a given rat, and $\bar{S}$ is the average EMG profile for a given group; $\tau$ represents the percent gait cycle, and $\sigma$ represents the proportion of the gait cycle during which the swing phase occurs (Equation (1)):

$$
\gamma=\frac{\int_{0}^{50 \% \sigma} \bar{s}(\tau) d \tau}{\int_{0}^{100 \%} \bar{s}(\tau) d \tau} \times 100
$$

Burst onset was defined as the time at which the EMG envelope rose above a threshold equal to 0.3 times the maximum EMG envelope amplitude. The end of a burst was defined as the time at which the envelope 
returned to its mean value. The latency from time of TO until burst onset was measured for each step, and the spread of latencies was compared between groups by calculating the standard deviation (SD) of latencies across steps for each animal, then averaging the SDs across animals in each group.

We have previously shown that RTT alone, as administered in this study, does not improve stepping in spinally contused rats [46]. In that study, five rats received the same type of RTT as used in the present study; we refer to this group as the RTT-only group. To verify that the functional improvements observed in the FES+RTT group were due to the combination of the FES with RTT rather than RTT alone, as aforementioned, we included kinematic and EMG burst results of the RTT-only group for comparison.

Over the course of this study, it was observed that sometimes rats not only did not step well but failed to step at all under one of two situations, in both of which there was no ankle flexion: (1) the rat did not lift one of its paws and the paw would end up being dragged backward as the treadmill pulled the paw behind the animal, and (2) the hind limb would remain suspended in the air in a withdrawal reflex. We developed a method to quantify these periods lacking regular ankle flexion. In general, when the rat was stepping, the ankle angle varied over a wide range of angles, while it was relatively constant when the rat's hind limb was either dragging or in withdrawal reflex (Figure 4). Dragging and withdrawal reflex were thus detected as prolonged periods of either extreme flexion (on the most acute end of the ankle angle range) or extreme extension (on the most obtuse end of the range), respectively. Thus, the ankle angle had to satisfy two general criteria to be classified as part of a period of dragging or withdrawal: (1) the absolute change in ankle angle had to remain below some threshold $\left(15^{\circ}\right.$ for the first-order difference with a step size of $250 \mathrm{~ms}$ ) for some threshold duration of time (2/3 of a second), and (2) the ankle angle had to be outside the range of $60^{\circ}$ to $130^{\circ}$. The thresholds were determined empirically by analyzing a sample of the videos and using the values that yielded accurate detection of the periods that matched the visually detected periods of dragging and withdrawal. Figure 4 shows examples of the detection in three rats. We defined $\lambda$ to be the percent of time spent dragging or in withdrawal.

To visualize the distribution of $\lambda$ for this small sample of rats in each group, the cumulative distribution for each group was plotted. First, the individual $\lambda$ values in each group were sorted in ascending order. Then the sorted values were cumulatively summed and the proportion of rats was plotted against the cumulative sum of $\lambda$ (Figure 5). An exactly uniform spread of $\lambda$ from 0 to 100 percent in a group would yield a straight diagonal line, as shown by the dashed black line. The cumulative distribution function (CDF) curve for a hypothetical group in which all rats stepped effectively all the time (i.e., if none of the rats dragged their hind limb or exhibited withdrawal reflex at all) would be a vertical line at $\lambda$ $=0$ percent. The farther the curve is to the right, or toward the 100 percent end of the $\lambda$ axis, the more the group collectively exhibited dragging or withdrawal reflex, and thus, the less stepping that occurred.

\section{Statistics}

For each EMG burst and kinematic measure, the average value was computed for each individual subject. The Mann-Whitney U test was then performed on these average values to test for statistically significant differences between groups. A binomial test was performed to determine whether the proportion of rats in each group that exhibited excessive dragging and withdrawal $(\lambda$ value greater than $20 \%$ ) was significantly different than the expected proportion in intact rats, which we estimated to be 10 percent based on observations from a previous study [47].

\section{RESULTS}

\section{Comparison of Hind-limb Stepping and Tibialis Anterior Electromyography Burst Characteristics}

We tested hind-limb treadmill stepping in spinally contused rats that were trained with FES of the TA muscle. In the FES+RTT group, the TA muscle was stimulated during the swing phase of RTT (Figure 3). In the RS group, the TA muscle received the same pattern of FES while the rats were in their cages. Thus, both groups received the same amount of patterned stimulation, but the stimulation in the FES+RTT group was precisely timed with hind-limb movements during stepping.

After 4 wk of training, tests were performed while the rat was on the treadmill, moving at $8 \mathrm{~cm} / \mathrm{s}$, with bodyweight support but without any robotic assistance or FES. No significant difference in step length ( 7.6 vs $11.4 \mathrm{~mm}$ in FES+RTT and RS groups, respectively; 
(a) RS (stim only)
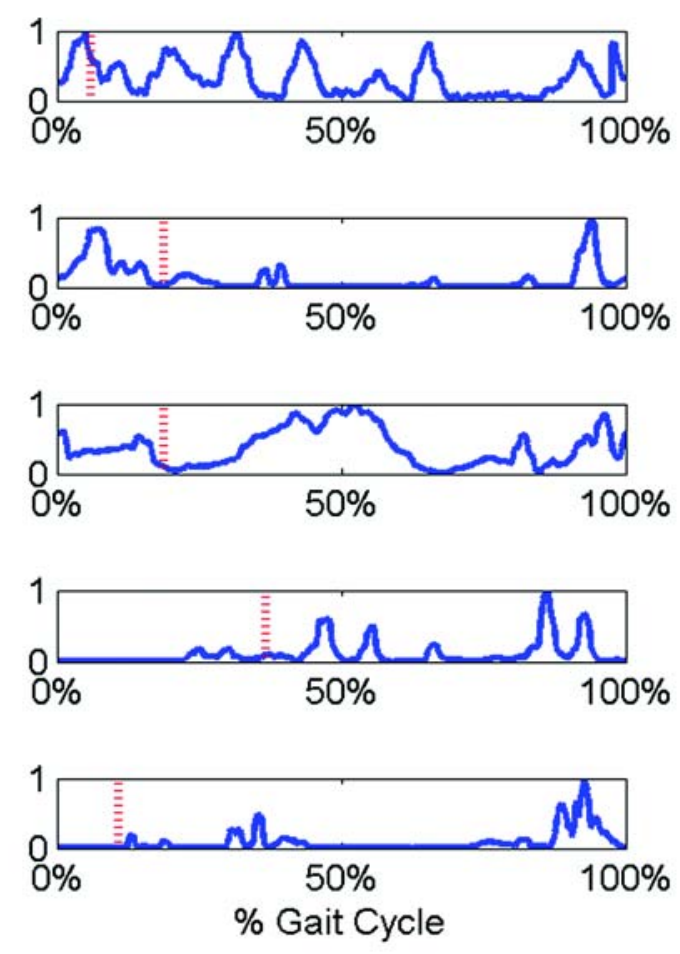

\section{(b) FES + RTT}
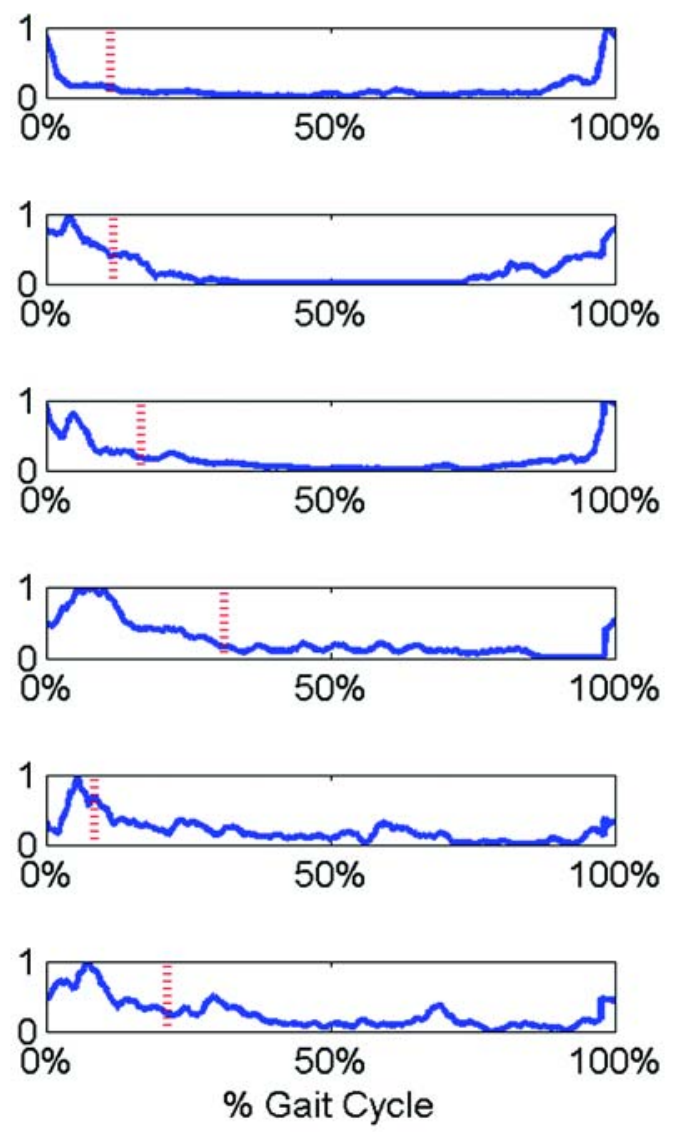

(c)

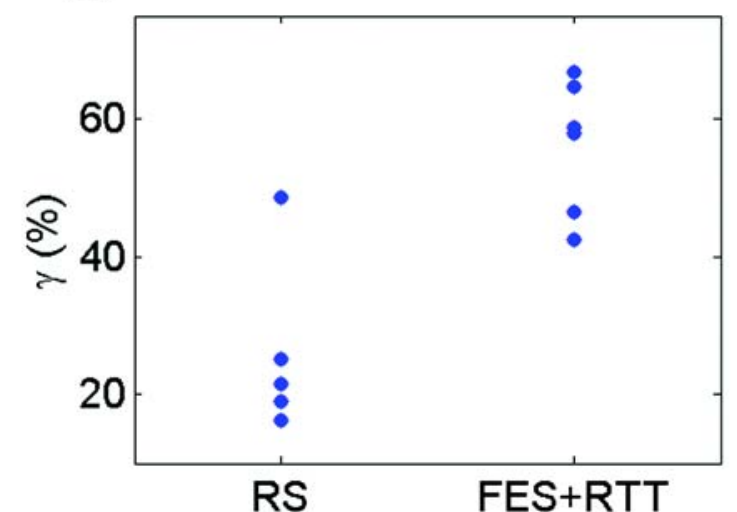

Figure 4.

Mean electromyography (EMG) profiles, normalized to maximum amplitude, from each rat in (a) randomly timed stimulation (RS) group and (b) functional electrical stimulation + robotic treadmill training (FES+RTT) group during testing (i.e., no stimulation or robotic forces applied). Dotted vertical lines indicate 50 percent of swing phase, corresponding with duration of stimulation applied during FES+RTT training. (c) Comparison of $\gamma$, concentration of EMG activation during first 50 percent of swing phase. Each dot represents mean value for individual rat. $\mathrm{Y}$ was significantly higher for FES+RTT group than RS group (Mann-Whitney $U$ test, $p=0.02$ ). 


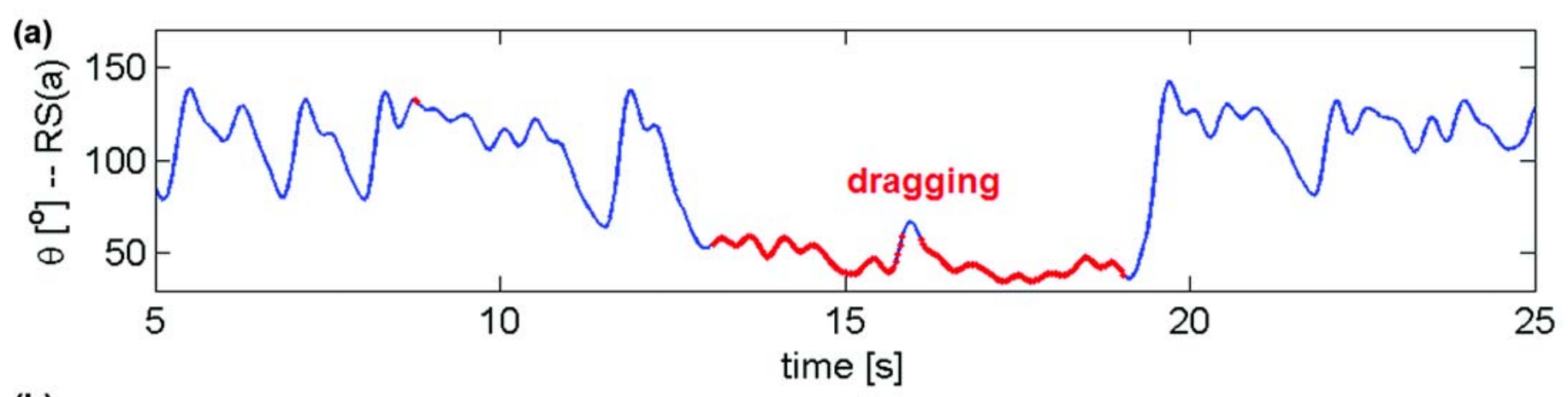

(b)

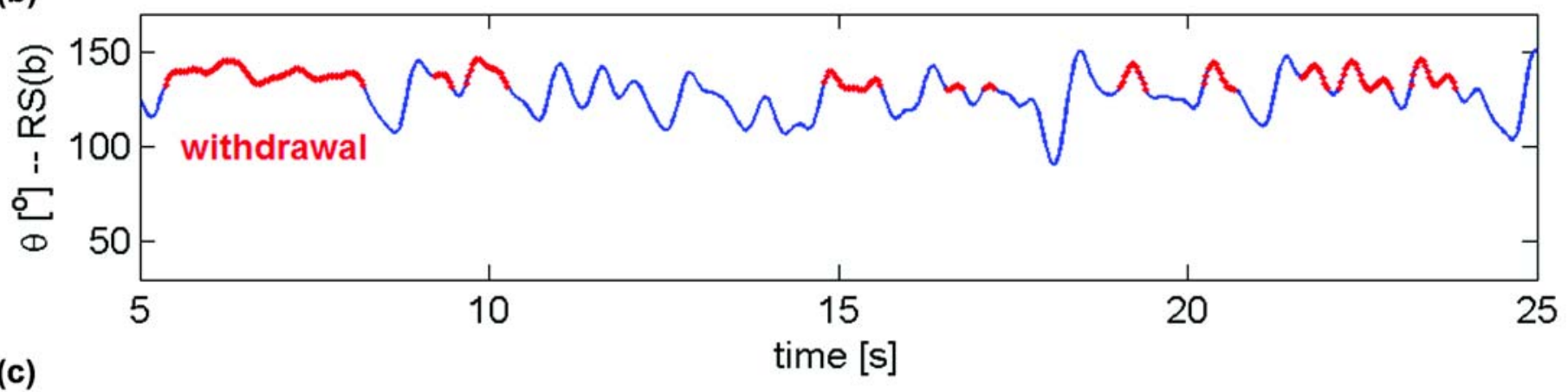

(c)

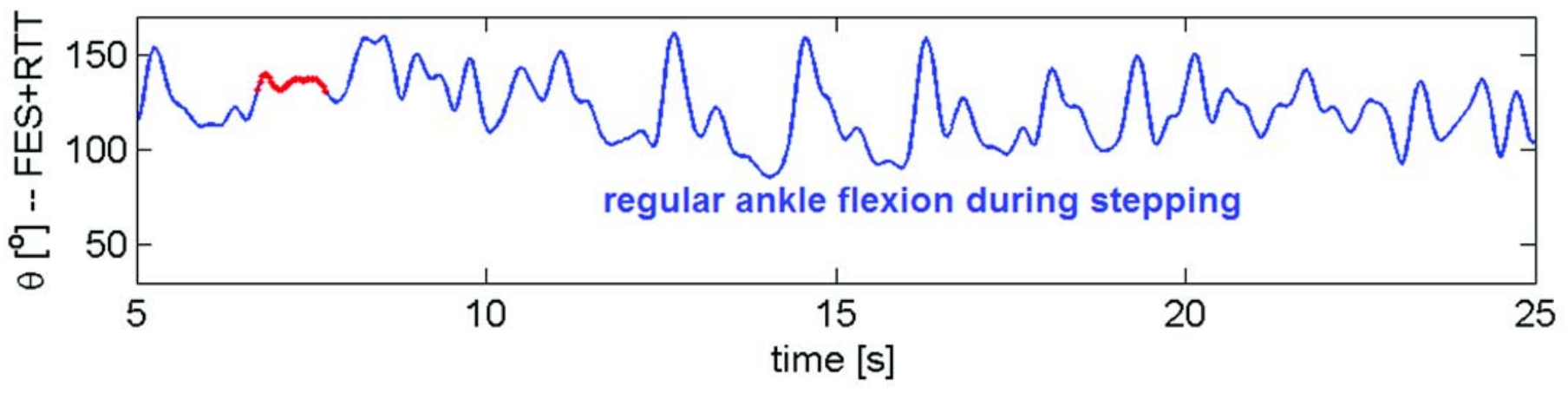

Figure 5.

Examples of ankle angle during testing from (a) randomly timed stimulation (RS) rat that exhibited dragging, (b) RS rat that exhibited several periods of withdrawal reflex, and (c) functional electrical stimulation + robotic treadmill training (FES+RTT) rat that did not exhibit dragging and exhibited only short period of detected withdrawal. Ankle angle during stepping is shown in solid blue, whereas detected periods of withdrawal or dragging are shown in red.

Figure 6(a)) or step height (28.5 vs $21.6 \mathrm{~mm}$ in FES+RTT and RS groups, respectively; Figure 6(b)) was found between the FES+RTT and RS groups. We previously examined kinematic characteristics in spinally contused rats that underwent RTT only [46] and compared these data with the FES+RTT group data. The FES+RTT group stepped significantly longer (Mann-Whitney U test, $p=0.04$; Figure 6(a)) and faster (Mann-Whitney $U$ test, $p=0.01$; Figure 6(c)) than the RTT-only group after
4 wk of training. Figure 6(c) shows the baseline data, available only for gait speed. The gait speeds of the FES+RTT group converged to higher and more tightly clustered values at final testing than in the other groups, although no significant differences were found in baseline gait speed between the FES+RTT group and the RTT-only or RS groups. Changes in gait speed from baseline to $4 \mathrm{wk}$ testing were significantly higher for FES+RTT (average increase of 83 steps $/ \mathrm{min}$ ) than RS 

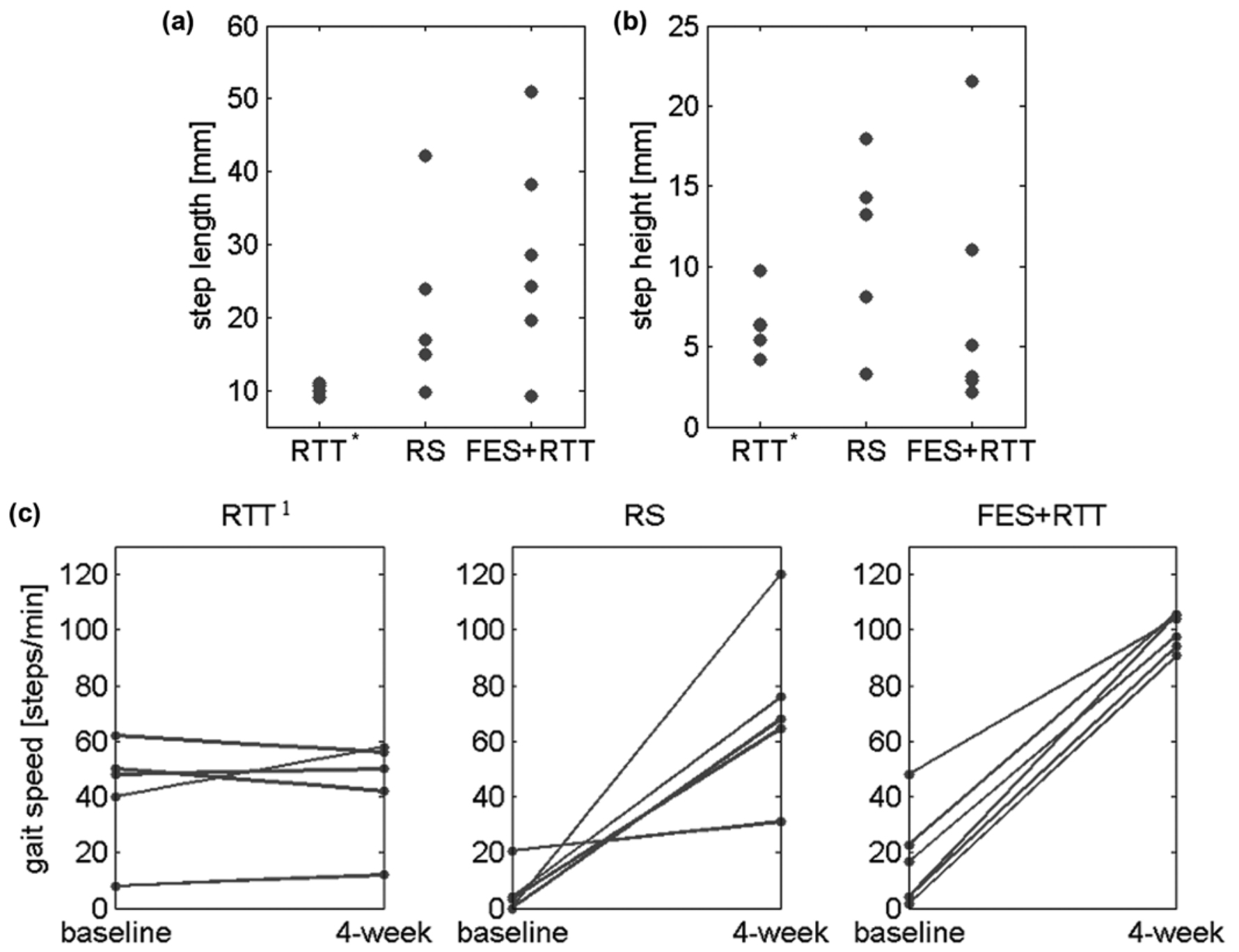

Figure 6.

Comparison of step kinematics during tests in which no robotic assistance or functional electrical stimulation (FES) was provided. (a) Each dot represents mean step length for each individual rat in robotic treadmill training (RTT)-only, randomly timed stimulation (RS), and FES+RTT groups; steps in FES+RTT group were significantly longer than in RTT-only group (Mann-Whitney U Test, $p=$ 0.04). (b) Step height. (c) Gait speed changes from baseline testing to final testing after 4 wk of training. Each line represents individual subject. Baseline to 4 wk changes in gait speed were significantly higher for FES+RTT group than for either RS or RTT-only groups (Mann-Whitney $U$ test, $p<0.01$ and $p=0.04$, respectively). "Data from Lee et al. [46].

(increase of 66 steps/min; Mann-Whitney $\mathrm{U}$ test, $p=$ 0.04 ) or RTT-only (increase of 2 steps/min; Mann-Whitney $\mathrm{U}$ test, $p=0.01$ ) (Figure 6(c)).

Characteristics of EMG activity recorded from the TA were compared between groups. Illustrative examples of TA EMG burst activity recorded simultaneously with ankle position during testing are shown in Figure 7(a)-(d) for two rats from the FES+RTT group and two rats from the RS group. EMG bursts recorded from the TA were on average 94.5 percent more frequent in the FES+RTT group than in the RS group (Mann-Whitney $\mathrm{U}$ test, $p=$ 0.01; Figure 7(e)).

Not only did the FES+RTT group produce more EMG burst activity, but the bursts appeared to be better coordinated with hind-limb stepping as detected by the robotic device (Figure 7). The RS group showed irregular 
(a)
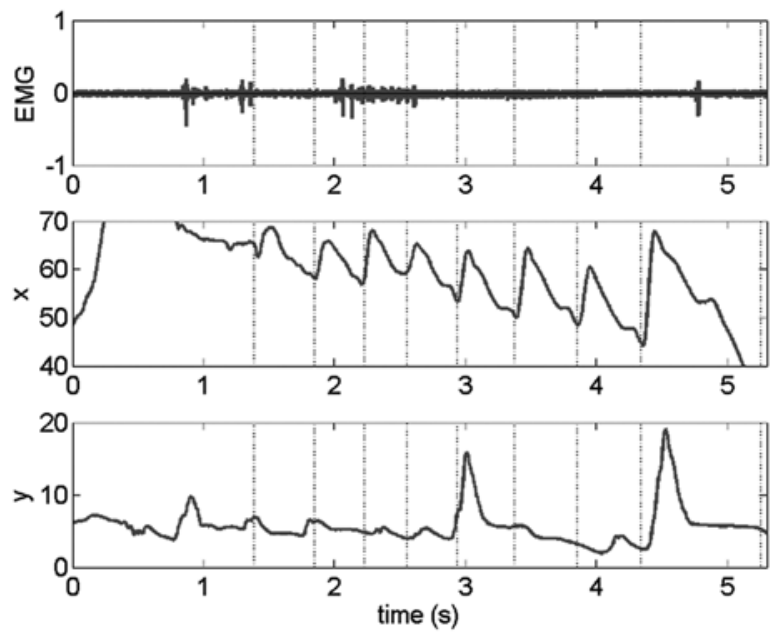

(c)
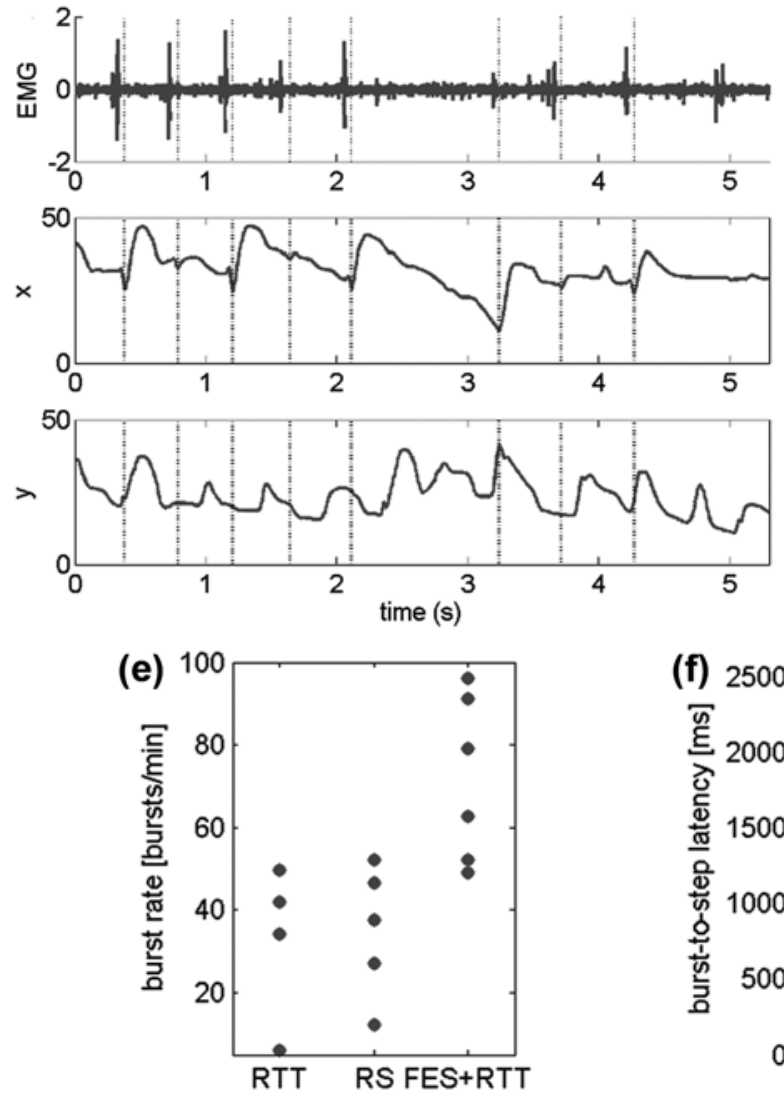

(b)
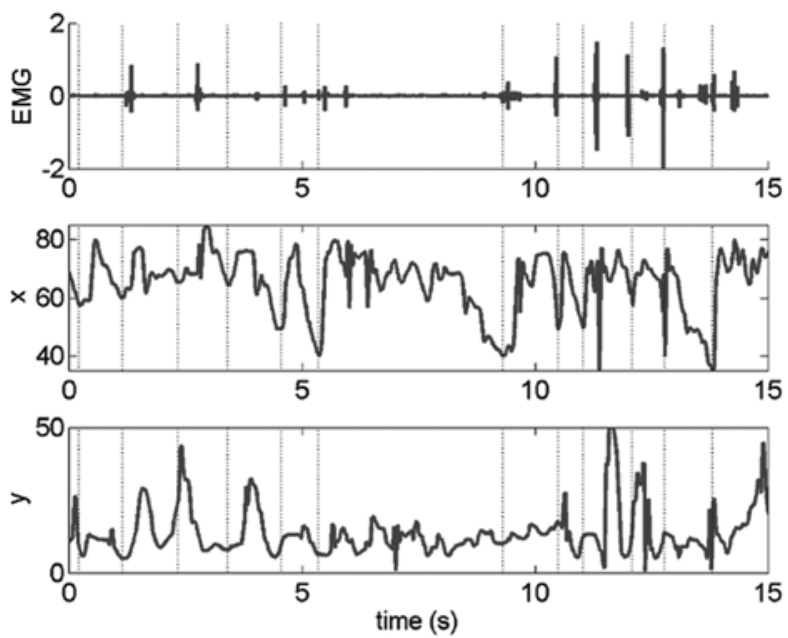

(d)
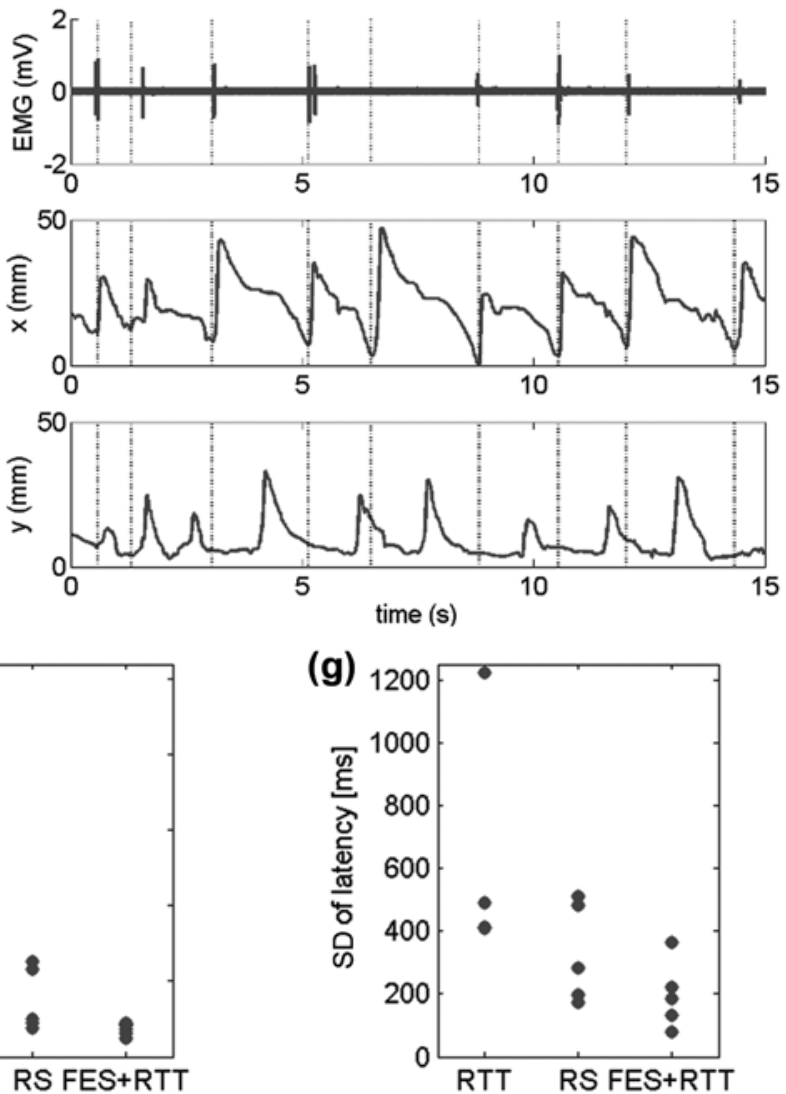

Figure 7.

Comparison of electromyography (EMG) burst activity. (a)-(b) Illustrative examples of tibialis anterior (TA) EMG burst activity and simultaneously recorded ankle position shown for two randomly timed stimulation (RS) rats and (c)-(d) two functional electrical stimulation (FES) + robotic treadmill training (RTT) rats. (a)-(d) Top trace is TA EMG (in millivolts) and middle and bottom traces are horizontal and vertical position (in millimeters) of ankle, respectively. Detected step cycles (beginning with toe-off) are demarcated by dotted vertical lines. These data were collected during tests of independent stepping on treadmill and no FES or assistive robotic forces were applied. (e) Mean burst rate for each RTT-only, RS, and FES+RTT rat. (f) Mean burst-to-step latency for each rat. (g) Standard deviation (SD) of burst-to-step latency across steps for each rat. 
patterns of burst EMG activity (see EMG in Figure 7(a)), whereas the FES+RTT group exhibited more consistent EMG bursting (see EMG in Figure 7(c)-(d)). Changes in ankle position were consistently timed with EMG bursts in the FES+RTT group (Figure 7(c)-(d)) but not the RS group (Figure 7(a)-(b)), i.e., each TA burst corresponds with a single step (indicated by dashed vertical lines in Figure 7(a)-(d)) that visually appeared more consistent in the FES+RTT group than the RS group. To quantify the association of EMG bursts with hind-limb stepping movements, the latency between EMG burst onset and change in ankle position corresponding with weight-bearing step cycles was computed. The burst-to-step latency of the FES+RTT group (72 bursts/min on average) was not significantly different from that of the RS group, although the average was 46 percent shorter than that of the RS group (35 bursts/min on average; Mann-Whitney U test, $p=0.1$; Figure 7(f)). The latency of the FES+RTT group was significantly shorter than in the RTT-only group (Mann-Whitney $\mathrm{U}$ test, $p=0.01$ ). FES+RTT also resulted in more consistent burst-to-step latencies on average, as can be seen from a comparison of the SD of the latencies (634 ms for RTT-only vs $329 \mathrm{~ms}$ for RS vs $195 \mathrm{~ms}$ for FES+RTT, Figure 7(g)), but the SD of the latency for the FES+RTT group was significantly different only from the RTT-only group (Mann-Whitney U test, $p=0.01$ ).

\section{Modulation of Electromyography Activation Patterns}

The average EMG activation profile from the TA muscle during a gait cycle was computed and is shown for each RS rat and FES+RTT rat in Figure 4(a)-(b), respectively. The RS group's profiles did not show any distinguishable patterns with respect to the gait cycle, and there was little consistency across animals in the RS group. In contrast, the FES+RTT activation profiles consistently exhibited a single peak right around TO $(0 \%$ gait cycle), usually just proceeding TO. This is approximately the same time that stimulation was delivered during training for the FES+RTT group; namely, during approximately the first 50 percent of the swing cycle (Figure 3(b)). The concentration of EMG during this first half of the swing cycle was computed as $\gamma$, and Figure 4(c) shows the comparison between groups. The difference in $\gamma$ between groups (mean \pm SD: $26.2 \% \pm 13.4 \%$ for RS vs $55.7 \% \pm 12.0 \%$ for FES+RTT) was statistically significant (Mann-Whitney U test, $p=0.02$ ).

\section{Recovery of Ankle Movements During Stepping}

The TA is one of the primary muscles that controls ankle flexion during stepping [53]. To determine whether the changes in TA activity were correspondingly reflected in improvements in ankle flexion, we performed a kinematic analysis of the ankle range of motion during stepping. The RS group did not consistently perform ankle flexion during stepping because the hind limb either dragged or was withdrawn (Figure 5(a)-(b)). In contrast, the FES+RTT group performed more consistent ankle flexion and there was less time spent in hind-limb dragging or withdrawal (Figure 5(c)). We calculated the percentage of time during testing that the ankle failed to consistently perform flexion and instead the paw dragged or was maintained in a withdrawn position. Figure 8 shows the CDF of the percentage of time that the rats in both groups exhibited dragging or withdrawal. Four of the RS rats but only one of the FES+RTT rats exhibited excessive dragging or withdrawal reflex (i.e., greater than 20 percent of the time; Figure 8). The proportion of the RS group exhibiting excessive dragging or withdrawal (4/5 rats) was significantly greater

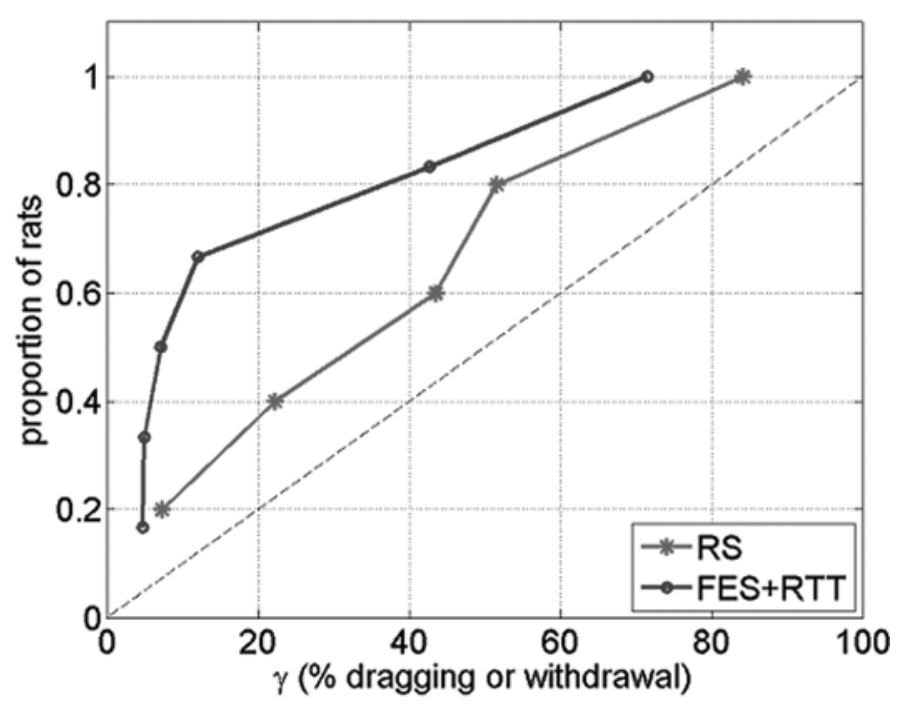

Figure 8.

Cumulative distributions of $\lambda$ (percent time spent dragging or in withdrawal reflex) for randomly timed stimulation (RS) rats $\left({ }^{*}\right)$ and functional electrical stimulation + robotic treadmill training (FES+RTT) rats (o). Dashed black diagonal line shows distribution for uniformly distributed set of $\lambda$ values. Most (4 of 6 ) rats in FES+RTT group exhibited dragging and withdrawal less than 15 percent of time, whereas only 1 of 5 rats in RS group did not exhibit excessive dragging. 
than the expected proportion in normal rats (binomial test, $p=0.01$ [47]). In contrast, the proportion of the FES+RTT group with excessive dragging or withdrawal (2/6 rats) was not different than the expected normal proportion (binomial test, $p=0.10$ ).

\section{DISCUSSION}

The results of our first investigation using the integrated FES+RTT system reveal a potential to enhance neuromuscular control after SCI by coordinating FES with RTT. Rats that underwent stimulation therapy of the TA muscle timed to robot-controlled stepping (FES+RTT group) exhibited a number of important differences compared with rats that received the same amount and pattern of TA stimulation but independently of hind-limb movement (RS group). First, the FES+RTT group stepped at a faster rate and produced more EMG burst activity in the TA with a shorter burst-to-step delay. Second, the EMG activation during a gait cycle was more consistent across the FES+RTT group than the RS group and more closely corresponded with the stimulation profile, showing a peak in TA EMG activity at approximately the same time in the gait cycle that FES was applied during training. Third, the improved TA activity likely contributed to the FES+RTT group's tendency to generate more regular ankle flexion and exhibit less dragging or withdrawal reflex than the RS group. These findings suggest that combining TA stimulation with afferent feedback generated during swing improved the neurophysiological control of the TA motor pools better than patterned stimulation alone. On average, the FES+RTT group also produced steps that were longer but not as high as in the RS group, which indicated more efficient stepping in general; while these differences were not statistically significant, they may have contributed to the faster stepping rate of the FES+RTT group.

\section{Implications for Advancing Gait Rehabilitation}

Some studies have shown that patterned stimulation alone, comparable with what was used in the RS group, can improve corticospinal excitability, which in turn is linked to enabling rehabilitation in patients with SCI [28$30,32]$. The present study demonstrates that coordinating FES with treadmill training in animals with SCI leads to better functional outcome than FES alone. Given the critical role of afferent feedback in the rehabilitative effects of treadmill training, these results are consistent with our hypothesis that FES may be used to reinforce the afferent feedback generated during treadmill training.

Clinical studies have already shown that combining FES with RTT can enhance locomotor rehabilitation in patients with SCI [8] and that similar long-term gains can be achieved with RTT alone [25]. Yet, perhaps coordinating FES with RTT differently than done in these studies can yield greater improvements in the control of walking for patients with SCI. Another group has also combined FES specifically with RTT and has even integrated the control of the stimulator with the gait-training robot, as in our system, so as to provide the capability for automated and precise coordinated control [54]. However, the details of how the stimulation is programmed to the gait cycle is lacking, and while the feasibility of using this system has been demonstrated [55], to our knowledge, results showing the effect on gait kinematics or underlying EMG activity have not been published.

We have developed a system that integrates FES control with RTT and is capable of delivering FES in accordance with the stepping that occurs during RTT. In contrast to our FES+RTT therapy, FES in clinical practice is applied to provide immediate assistance whenever the patient desires to walk. Our intention is not so much to affect a particular gait through FES during training but to encourage appropriate changes in the neuromotor circuitry to enable long-term improvements in stepping. If systematically coordinated with RTT, perhaps FES's influence on spinal circuitry can be better controlled and enable patients to eventually walk without artificial assistance. At least one group, which has investigated the rehabilitative effect of combining FES with treadmill training, has suggested that FES not only strengthens muscles but might also activate sensory pathways in a way that improves coordination [56]. Our FES+RTT system is capable of timing the FES precisely with the robotcontrolled gait pattern in an attempt to reinforce such afferent feedback [48].

The present study also shows the feasibility of studying this therapy in an animal model. We believe that a more systematic investigation is needed on how FES might be coordinated with afferent activity to influence spinal circuitry in order to achieve a better therapy. Other efforts are being made to understand the neuromuscular changes underlying the effects of FES on the recovery of stepping. One group uses FES of unloaded hind limbs but uses feedback control to encourage a desired pattern of hip flexion 
and extension. This approach is being studied in animals and has shown the potential to improve restoration of longterm stepping capability [36-37]. In conjunction with such work, the results of this study raise the possibility of enhancing spinal circuitry involved in stepping, and thereby encouraging long-term benefits for stepping after SCI, with further FES therapy development.

\section{Evidence for Enhanced Motoneuron Output: Changes in Electromyography Activity in Tibialis Anterior}

We hypothesized that timing FES with afferent activity generated during RTT better promotes appropriate changes in the spinal cord than FES alone. We expected that any reorganization and enhancement of spinal cord circuitry that may have been induced by FES+RTT therapy would manifest itself in the ability to control muscle activation to produce effective steps. Thus, we used EMG measures as one indicator of plasticity, in particular at the level of the motor pool. EMG patterns recorded from hind-limb muscles have been shown to reflect training-enhanced plasticity [57], and EMG behavior has been accepted as a representation of damage to or recovery of the neuromotor control that underlies muscle output [5861]. The EMG activation profiles of the FES+RTT group showed more consistent timing of muscle activation to the swing phase of the gait cycle than those of the RS group. The delay between the EMG burst and the resulting step may also give some indication of the effectiveness of the rat's neuromotor control, which perhaps resulted in the consistently faster cadence in the FES+RTT group than in the RS group. We interpret the shorter, more consistent burst-to-step latencies and the organized pattern of the EMG profile in the FES+RTT group to signify improved neuromotor control over ankle flexors during the appropriate phase of the step cycle. These improvements in EMG coincided with improvements in ankle kinematics. The FES+RTT group regularly flexed their ankle during testing, as would be expected in normal stepping, more so than the RS group. Differences in EMG could also result from differences at the level of the peripheral nerve or muscle. However, the capacity for FES+RTT to enable spinally contused rats to generate consistent EMG burst patterns with peaks in the beginning of, or just prior to, the swing phase compared with FES alone support the interpretation that FES+RTT resulted in a more consistent recruitment of the TA motor pools when ankle flexion was most needed.

\section{Possible Influence of FES+RTT on Spinal Circuitry}

Our FES+RTT system was designed to apply stimulation in such a way as to reinforce afferent activity expected just prior to and during the initial portion of the swing phase [48]. From the present study, we cannot determine whether or how FES+RTT encouraged plasticity within the spinal circuits. However, if coordinating FES with RTT indeed reinforced spinal circuitry that controls stepping, we believe the most plausible mechanisms are that the applied FES either increased the afferent drive into central pattern generators or reinforced the afferent modulation of motor neuron synapses.

There is evidence that patterned stimulation alone, i.e., not timed with afferent feedback, was sufficient to induce short-term plasticity in the spinal circuitry [29-30,62]. A single session of FES of the CPN was sufficient to enhance excitation in the corticospinal pathways controlling the TA in nondisabled subjects [30] and subjects with SCI [29]. In these studies, FES was applied while the subjects were seated and the maximal effects were observed 40 to $45 \mathrm{~min}$ poststimulation. We applied FES therapy to the RS group over the course of $4 \mathrm{wk}$ and tests were performed at least $24 \mathrm{~h}$ after the last therapy session. Our findings suggested that in addition to the short-term effects, there were longterm effects of patterned FES when timed to stepping that contributed to overall improved stepping function. The major difference between RS versus FES+RTT therapy was the absence of afferent feedback generated during stepping. Given the importance of appropriate sensory feedback in promoting synaptic efficacy and improvements in step kinematics [63], we hypothesize that this coordination of FES with the step cycle during RTT further encouraged spinal plasticity, beyond what is achieved by FES alone, by reinforcing afferent input into motor neurons during the step cycle.

Even if our hypothesis is correct, there still remains the question of precisely what afferent activity is being reinforced. Jung et al. have developed and tested a unique FES therapy in rats that consisted of stimulating hip flexor and extensor muscles to drive the hind limb through a desired trajectory [36-37]. In contrast with the FES+RTT employed in the present study, the stimulation and the subsequent hind-limb movements occurred in the absence of weight bearing on the hind limb. Improved functional recovery was achieved even though loadrelated sensory cues were not generated during this therapy and may have been a result of encouraging appropriate proprioceptive patterns of activity [36]. 
Recent studies have reported that synaptic inputs onto motor neurons found in the locomotor-generating region of the spinal cord were increased by treadmill training in spinally transected rats [64-65]. There is also evidence that treadmill training restored a normal balance of excitatory to inhibitory synapses, thereby improving motor neuron activity [45]. Results from this study, as well as the literature, indicate that FES alone can have some benefit in improving locomotor capability, such as improved step length and improved spinal reflexes. We hypothesize that FES is capable of making widespread changes in spinal circuitry, such as increasing the number of synapses to motor neurons, but such changes are only one part of the equation in converting nonfunctional spinal circuits to functional [66-67]. Further synaptic modifications are likely necessary for synaptic potentiation in step-generating circuits, and perhaps timing of FES with afferent activity encourages these modifications.

\section{Limitations}

Our study only investigated the benefit of FES timed to ankle flexion over RS alone but did not consider whether it provided any benefit over RTT alone. Previous studies have reported a beneficial effect of treadmill training in spinally contused rats $[47,68]$. However, such benefits do not result when high levels of robotic assistance are applied during the training [46]. In an attempt to ensure that any improvements in the FES+RTT group over the RS group were primarily a result of the FES+RTT group receiving FES paired with RTT and not a result of RTT itself, the RTT protocol used in the present study was similar to the full robotic assistance that we examined previously in spinally contused rats [46]. Although we cannot conclude from the present results the extent to which RTT contributed to the benefits of FES+RTT, we administered RTT at high levels of assistance, such that it was unlikely to lead to improvements in kinematics or EMG. Furthermore, comparisons between step kinematics and EMG burst activity of the FES+RTT group in the present study and the full assistance rats from Lee et al. (Figures 6-7) indicate that FES+RTT leads to better stepping than RTT alone [46]. These results are corroborated by a clinical case study that showed that improvements in walking could be attained by a combination of FES and RTT but not by applying FES and RTT separately [8]. Further investigation is needed to compare FES+RTT with RTT at lower levels of robotic assistance.
This was a low-powered study. Although the average differences between groups were generally consistent with the hypothesis that the effects of patterned stimulation alone were enhanced by timing the stimulation to RTT, we cannot make any conclusions without conducting this comparison on a larger number of subjects. Finally, although baseline tests were performed and the two groups were balanced based on baseline performance, there was a lack of baseline data for some measures. So it is not certain, for example, how RS or FES+RTT treatments may have influenced EMG bursting patterns over time.

\section{CONCLUSIONS}

Although prior studies have shown some capability of FES in and of itself to modify corticospinal circuitry, the present work illustrates the benefit of timing stimulation to robot-controlled stepping. The FES+RTT therapy helped to organize and increase the consistency of the EMG profile and encouraged the use of ankle flexion during stepping. This study was an initial step toward developing a rodent model of FES therapy that enhances activity-dependent plasticity associated with treadmill training [48]. The extent to which the FES used in the present study reinforced afferent activity is unknown and needs to be investigated in further studies. One such study might entail investigating how hind-limb loading, because the body-weight support level is varied, affects the rehabilitation achieved by FES+RTT training. The ability to promote rehabilitative changes in the spinal cord using FES and RTT could lead to a relatively lowrisk, practical therapy for restoring walking capability to patients with SCI.

\section{ACKNOWLEDGMENTS}

Author Contributions:

Study concept and design: D. S. Won, R. D. de Leon.

FES+RTT system development and testing: D. S. Won, S. Askari, T. Chao.

Animal experimentation: S. Askari, T. Chao, R. D. de Leon.

Data analysis: S. Askari, D. S. Won, T. Chao.

Interpretation of results: D. S. Won, R. D. de Leon.

Drafting of manuscript: D. S. Won.

Critical revision of manuscript for important intellectual content:

S. Askari, T. Chao, R. D. de Leon, D. S. Won.

Statistical analysis: R. D. de Leon, D. S. Won. 
Financial Disclosures: The authors have declared that no competing interests exist.

Funding/Support: This material was based on work supported by the National Institutes of Health (NIH) (grants 1SC2NS075743 and 1RO1NS055911).

Additional Contributions: The authors would like to gratefully acknowledge Lauren Conn, Pamela See, Elizabeth Partida, Cheryl Chow, and Teresa Lazzaretto for their hard work and assistance with animal training and handling. Mr. Askari is now with the University of California, Irvine.

Institutional Review: All procedures with rats were carried out in accordance with NIH guidelines and the protocols were approved by the Institutional Animal Care and Use Committee at California State University, Los Angeles.

\section{REFERENCES}

1. Faghri PD, Rodgers MM, Glaser RM, Bors JG, Ho C, Akuthota $P$. The effects of functional electrical stimulation on shoulder subluxation, arm function recovery, and shoulder pain in hemiplegic stroke patients. Arch Phys Med Rehabil. 1994;75(1):73-79. [PMID:8291967]

2. Powell J, Pandyan AD, Granat M, Cameron M, Stott DJ. Electrical stimulation of wrist extensors in poststroke hemiplegia. Stroke. 1999;30(7):1384-89.

[PMID:10390311] http://dx.doi.org/10.1161/01.STR.30.7.1384

3. Salter A-C, Bagg SD, Creasy JL, Romano C, Romano D, Richmond FJ, Loeb GE. First clinical experience with BION implants for therapeutic electrical stimulation. Neuromodulation. 2004;7(1):38-47. [PMID:22151125]

http://dx.doi.org/10.1111/j.1525-1403.2004.04005.x

4. Rodgers MM, Glaser RM, Figoni SF, Hooker SP, Ezenwa BN, Collins SR, Mathews T, Suryaprasad AG, Gupta SC. Musculoskeletal responses of spinal cord injured individuals to functional neuromuscular stimulation-induced knee extension exercise training. J Rehabil Res Dev. 1991;28(4):

19-26. [PMID:1941645]

http://dx.doi.org/10.1682/JRRD.1991.10.0019

5. Thrasher TA, Flett HM, Popovic MR. Gait training regimen for incomplete spinal cord injury using functional electrical stimulation. Spinal Cord. 2006;44(6):357-61. [PMID:16249784] http://dx.doi.org/10.1038/sj.sc.3101864

6. Faghri P, Glaser RM, Figoni SF, Miles DS, Gupta SC. Feasibility of using two FNS exercise modes for spinal cord injured patients. Clin Kinesiol. 1989;43(3):62-68.

7. Gruner JA, Glaser RM, Feinberg SD, Collins SR, Nussbaum NS. A system for evaluation and exercise-conditioning of paralyzed leg muscles. J Rehabil Res Dev. 1983;20(1):21-30. [PMID:6887063]
8. Hardin E, Kobetic R, Murray L, Corado-Ahmed M, Pinault G, Sakai J, Bailey SN, Ho C, Triolo RJ. Walking after incomplete spinal cord injury using an implanted FES system: A case report. J Rehabil Res Dev. 2007;44(3):333-46. [PMID:18247230]

http://dx.doi.org/10.1682/JRRD.2007.03.0333

9. Peckham PH, Mortimer JT, Marsolais EB. Alteration in the force and fatigability of skeletal muscle in quadriplegic humans following exercise induced by chronic electrical stimulation. Clin Orthop Relat Res. 1976;(114):326-33. [PMID:1083324]

10. Ragnarsson KT. Functional electrical stimulation after spinal cord injury: Current use, therapeutic effects and future directions. Spinal Cord. 2008;46(4):255-74.

[PMID:17846639] http://dx.doi.org/10.1038/sj.sc.3102091

11. Kobetic R, Marsolais EB. Synthesis of paraplegic gait with multichannel functional neuromuscular stimulation. IEEE Trans Rehabil Eng. 1994;2(2):66-79.

http://dx.doi.org/10.1109/86.313148

12. Graupe D, Cerrel-Bazo H, Kern H, Carraro U. Walking performance, medical outcomes and patient training in FES of innervated muscles for ambulation by thoracic-level complete paraplegics. Neurol Res. 2008;30(2):123-30.

[PMID:18397602] http://dx.doi.org/10.1179/174313208X281136

13. Bajd T, Kralj A, Stefancic M, Lavrac N. Use of functional electrical stimulation in the lower extremities of incomplete spinal cord injured patients. Artif Organs. 1999;23(5): 403-9. [PMID:10378929] http://dx.doi.org/10.1046/j.1525-1594.1999.06360.x

14. Peckham PH, Knutson JS. Functional electrical stimulation for neuromuscular applications. Annu Rev Biomed Eng. 2005;7:327-60. [PMID:16004574] http://dx.doi.org/10.1146/annurev.bioeng.6.040803.140103

15. Bajd T, Kralj A, Turk R, Benko H, Sega J. The use of a four-channel electrical stimulator as an ambulatory aid for paraplegic patients. Phys Ther. 1983;63(7):1116-20. [PMID:6602994]

16. Bryden AM, Kilgore KL, Kirsch RF, Memberg WD, Peckham HP, Keith MW. An implanted neuroprosthesis for high tetraplegia. Top Spinal Cord Inj Rehabil. 2005;10(3):38-52. http://dx.doi.org/10.1310/G9T5-CCK9-Y0WT-4714

17. Popovic MR, Popovic DB, Keller T. Neuroprostheses for grasping. Neurol Res. 2002;24(5):443-52.

[PMID:12117312] http://dx.doi.org/10.1179/016164102101200311

18. Knutson J, Audu M, Triolo R. Interventions for mobility and manipulation after spinal cord injury: A review of orthotic and neuroprosthetic options. Top Spinal Cord Inj Rehabil. 2006;11(4):61-81. http://dx.doi.org/10.1310/9UU4-KL3V-CPL2-Q7VF 
19. Braz GP, Russold M, Davis GM. Functional electrical stimulation control of standing and stepping after spinal cord injury: A review of technical characteristics. Neuromodulation. 2009;12(3):180-90. [PMID:22151359] http://dx.doi.org/10.1111/j.1525-1403.2009.00213.x

20. Graupe D, Davis R, Kordylewski H, Kohn KH. Ambulation by traumatic T4-12 paraplegics using functional neuromuscular stimulation. Crit Rev Neurosurg. 1998;8(4): 221-31. [PMID:9683682]

21. Stein RB, Everaert DG, Thompson AK, Chong SL, Whittaker M, Robertson J, Kuether G. Long-term therapeutic and orthotic effects of a foot drop stimulator on walking performance in progressive and nonprogressive neurological disorders. Neurorehabil Neural Repair. 2010;24(2): 152-67. [PMID:19846759] http://dx.doi.org/10.1177/1545968309347681

22. Field-Fote EC. Spinal cord control of movement: Implications for locomotor rehabilitation following spinal cord injury. Phys Ther. 2000;80(5):477-84. [PMID:10792858]

23. Kobetic R, Triolo RJ, Uhlir JP, Bieri C, Wibowo M, Polando G, Marsolais EB, Davis JA Jr, Ferguson KA. Implanted functional electrical stimulation system for mobility in paraplegia: A follow-up case report. IEEE Trans Rehabil Eng. 1999;7(4):390-98. [PMID:10609626] http://dx.doi.org/10.1109/86.808942

24. Field-Fote EC. Combined use of body weight support, functional electric stimulation, and treadmill training to improve walking ability in individuals with chronic incomplete spinal cord injury. Arch Phys Med Rehabil. 2001; 82(6):818-24. [PMID:11387589] http://dx.doi.org/10.1053/apmr.2001.23752

25. Nooijen CF, Ter Hoeve N, Field-Fote EC. Gait quality is improved by locomotor training in individuals with SCI regardless of training approach. J Neuroeng Rehabil. 2009; 6:36-46. [PMID:19799783] http://dx.doi.org/10.1186/1743-0003-6-36

26. Barbeau H, Ladouceur M, Mirbagheri MM, Kearney RE. The effect of locomotor training combined with functional electrical stimulation in chronic spinal cord injured subjects: Walking and reflex studies. Brain Res Brain Res Rev. 2002;40(1-3):274-91. [PMID:12589926] http://dx.doi.org/10.1016/S0165-0173(02)00210-2

27. Everaert DG, Thompson AK, Chong SL, Stein RB. Does functional electrical stimulation for foot drop strengthen corticospinal connections? Neurorehabil Neural Repair. 2010;24(2):168-77. [PMID:19861590] http://dx.doi.org/10.1177/1545968309349939

28. Knash ME, Kido A, Gorassini M, Chan KM, Stein RB. Electrical stimulation of the human common peroneal nerve elicits lasting facilitation of cortical motor-evoked potentials. Exp Brain Res. 2003;153(3):366-77.

\section{[PMID:14610631]}

http://dx.doi.org/10.1007/s00221-003-1628-9

29. Thompson AK, Lapallo B, Duffield M, Abel BM, Pomerantz F. Repetitive common peroneal nerve stimulation increases ankle dorsiflexor motor evoked potentials in incomplete spinal cord lesions. Exp Brain Res. 2011; 210(1):143-52. [PMID:21360230]

http://dx.doi.org/10.1007/s00221-011-2607-1

30. Mang CS, Lagerquist O, Collins DF. Changes in corticospinal excitability evoked by common peroneal nerve stimulation depend on stimulation frequency. Exp Brain Res. 2010;203(1):11-20. [PMID:20217400]

http://dx.doi.org/10.1007/s00221-010-2202-x

31. Khaslavskaia S, Ladouceur M, Sinkjaer T. Increase in tibialis anterior motor cortex excitability following repetitive electrical stimulation of the common peroneal nerve. Exp Brain Res. 2002;145(3):309-15. [PMID:12136380] http://dx.doi.org/10.1007/s00221-002-1094-9

32. Khaslavskaia S, Sinkjaer T. Motor cortex excitability following repetitive electrical stimulation of the common peroneal nerve depends on the voluntary drive. Exp Brain Res. 2005;162(4):497-502. [PMID:15702321] http://dx.doi.org/10.1007/s00221-004-2153-1

33. Colombo G, Wirz M, Dietz V. Driven gait orthosis for improvement of locomotor training in paraplegic patients. Spinal Cord. 2001;39(5):252-55. [PMID:11438840] http://dx.doi.org/10.1038/sj.sc.3101154

34. Hesse S, Uhlenbrock D, Werner C, Bardeleben A. A mechanized gait trainer for restoring gait in nonambulatory subjects. Arch Phys Med Rehabil. 2000;81(9):1158-61. [PMID:10987154] http://dx.doi.org/10.1053/apmr.2000.6280

35. Nessler JA, Timoszyk W, Merlo M, Emken JL, Minakata K, Roy RR, de Leon RD, Edgerton VR, Reinkensmeyer DJ. A robotic device for studying rodent locomotion after spinal cord injury. IEEE Trans Neural Syst Rehabil Eng. 2005;13(4):497-506. [PMID:16425832]

36. Jung R, Belanger A, Kanchiku T, Fairchild M, Abbas JJ. Neuromuscular stimulation therapy after incomplete spinal cord injury promotes recovery of interlimb coordination during locomotion. J Neural Eng. 2009;6(5):055010.

[PMID:19721184] http://dx.doi.org/10.1088/1741-2560/6/5/055010

37. Fairchild MD, Kim SJ, Iarkov A, Abbas JJ, Jung R. Repetetive hindlimb movement using intermittent adaptive neuromuscular electrical stimulation in an incomplete spinal cord injury rodent model. Exp Neurol. 2010;223(2): 623-33. [PMID:20206164] http://dx.doi.org/10.1016/j.expneurol.2010.02.011

38. Dietz V, Duysens J. Significance of load receptor input during locomotion: A review. Gait Posture. 2000;11(2):102-10. 


\section{[PMID: 10899663]}

http://dx.doi.org/10.1016/S0966-6362(99)00052-1

39. Conway BA, Hultborn H, Kiehn O. Proprioceptive input resets central locomotor rhythm in the spinal cat. Exp Brain Res. 1987;68(3):643-56. [PMID:3691733]

http://dx.doi.org/10.1007/BF00249807

40. Pearson KG, Misiaszek JE, Fouad K. Enhancement and resetting of locomotor activity by muscle afferents. In: Kiehn O, Harris-Warrick RM, Jordan LM, Hultborn H, Kudo N, editors. Neuronal mechanisms for generating locomotor activity. New York (NY): New York Academy of Sciences; 1998. p. 203-15.

41. Barbeau H, McCrea DA, O’Donovan MJ, Rossignol S, Grill WM, Lemay MA. Tapping into spinal circuits to restore motor function. Brain Res Brain Res Rev. 1999; 30(1):27-51. [PMID:10407124]

http://dx.doi.org/10.1016/S0165-0173(99)00008-9

42. Wolpaw JR, Tennissen AM. Activity-dependent spinal cord plasticity in health and disease. Annu Rev Neurosci. 2001; 24:807-43. [PMID:11520919]

http://dx.doi.org/10.1146/annurev.neuro.24.1.807

43. Edgerton VR, Roy RR. Activity-dependent plasticity of spinal locomotion: Implications for sensory processing. Exerc Sport Sci Rev. 2009;37(4):171-78.

[PMID:19955866]

44. Ollivier-Lanvin K, Krupka AJ, AuYong N, Miller K, Prilutsky BI, Lemay MA. Electrical stimulation of the sural cutaneous afferent nerve controls the amplitude and onset of the swing phase of locomotion in the spinal cat. J Neurophysiol. 2011;105(5):2297-2308. [PMID:21389308] http://dx.doi.org/10.1152/jn.00385.2010

45. Ichiyama RM, Broman J, Roy RR, Zhong H, Edgerton VR, Havton LA. Locomotor training maintains normal inhibitory influence on both alpha- and gamma-motoneurons after neonatal spinal cord transection. J Neurosci. 2011; 31(1):26-33. [PMID:21209186] http://dx.doi.org/10.1523/JNEUROSCI.6433-09.2011

46. Lee C, Won D, Cantoria MJ, Hamlin M, de Leon RD. Robotic assistance that encourages the generation of stepping rather than fully assisting movements is best for learning to step in spinally contused rats. J Neurophysiol. 2011; 105(6):2764-71. [PMID:21430272]

47. Heng C, de Leon RD. Treadmill training enhances the recovery of normal stepping patterns in spinal cord contused rats. Exp Neurol. 2009;216(1):139-47.

[PMID:19111541] http://dx.doi.org/10.1016/j.expneurol.2008.11.023

48. Chao T, Askari S, De Leon R, Won D. A system to integrate electrical stimulation with robotically controlled treadmill training to rehabilitate stepping after spinal cord injury. IEEE Trans Neural Syst Rehabil Eng. 2012;20(5):
730-37. [PMID:22692941]

http://dx.doi.org/10.1109/TNSRE.2012.2202292

49. Timoszyk WK, Nessler JA, Acosta C, Roy RR, Edgerton VR, Reinkensmeyer DJ, de Leon R. Hindlimb loading determines stepping quantity and quality following spinal cord transection. Brain Res. 2005;1050(1-2):180-89.

[PMID: 15979592]

http://dx.doi.org/10.1016/j.brainres.2005.05.041

50. Sławińska U, Majczyński H, Dai Y, Jordan LM. The upright posture improves plantar stepping and alters responses to serotonergic drugs in spinal rats. J Physiol. 2012;590(Pt 7): 1721-36. [PMID:22351637] http://dx.doi.org/10.1113/jphysiol.2011.224931

51. Winter DA, Yack HJ. EMG profiles during normal human walking: Stride-to-stride and inter-subject variability. Electroencephalogr Clin Neurophysiol. 1987;67(5):402-11. [PMID:2444408]

http://dx.doi.org/10.1016/0013-4694(87)90003-4

52. Arendt-Nielsen L, Sinkjær T. Quantification of human dynamic muscle fatigue by electromyography and kinematic profiles. J Electromyogr Kinesiol. 1991;1(1):1-8. [PMID:20719590] http://dx.doi.org/10.1016/1050-6411(91)90021-V

53. Gruner JA, Altman J, Spivack N. Effects of arrested cerebellar development on locomotion in the rat. Cinematographic and electromyographic analysis. Exp Brain Res. 1980;40(4):361-73. [PMID:7439280]

http://dx.doi.org/10.1007/BF00236145

54. Dohring ME, Daly JJ. Automatic synchronization of functional electrical stimulation and robotic assisted treadmill training. IEEE Trans Neural Syst Rehabil Eng. 2008; 16(3):310-13. [PMID:18586610] http://dx.doi.org/10.1109/TNSRE.2008.920081

55. McCabe JP, Dohring ME, Marsolais EB, Rogers J, Burdsall R, Roenigk K, Pundik S, Daly JJ. Feasibility of combining gait robot and multichannel functional electrical stimulation with intramuscular electrodes. J Rehabil Res Dev. 2008;45(7):997-1006. [PMID:19165689] http://dx.doi.org/10.1682/JRRD.2007.08.0124

56. Daly JJ, Zimbelman J, Roenigk KL, McCabe JP, Rogers JM, Butler K, Burdsall R, Holcomb JP, Marsolais EB, Ruff RL. Recovery of coordinated gait: Randomized controlled stroke trial of functional electrical stimulation (FES) versus no FES, with weight-supported treadmill and over-ground training. Neurorehabil Neural Repair. 2011;25(7):588-96. [PMID:21515871] http://dx.doi.org/10.1177/1545968311400092

57. Tillakaratne NJ, de Leon RD, Hoang TX, Roy RR, Edgerton VR, Tobin AJ. Use-dependent modulation of inhibitory capacity in the feline lumbar spinal cord. J Neurosci. 2002; 22(8):3130-43. [PMID:11943816] 
58. Dietz V, Müller R. Degradation of neuronal function following a spinal cord injury: Mechanisms and countermeasures. Brain. 2004;127(Pt 10):2221-31. [PMID:15269117]

59. Curt A, Dietz V. Electrophysiological recordings in patients with spinal cord injury: Significance for predicting outcome. Spinal Cord. 1999;37(3):157-65.

[PMID:10213324] http://dx.doi.org/10.1038/sj.sc.3100809

60. Lünenburger L, Bolliger M, Czell D, Müller R, Dietz V. Modulation of locomotor activity in complete spinal cord injury. Exp Brain Res. 2006;174(4):638-46.

[PMID:16761140] http://dx.doi.org/10.1007/s00221-006-0509-4

61. Valero-Cuevas FJ, Venkadesan M, Todorov E. Structured variability of muscle activations supports the minimal intervention principle of motor control. J Neurophysiol. 2009;102(1):59-68. [PMID:19369362] http://dx.doi.org/10.1152/jn.90324.2008

62. Perez MA, Field-Fote8 EC, Floeter MK. Patterned sensory stimulation induces plasticity in reciprocal ia inhibition in humans. J Neurosci. 2003;23(6):2014-18. [PMID:12657659]

63. Petruska JC, Ichiyama RM, Jindrich DL, Crown ED, Tansey KE, Roy RR, Edgerton VR, Mendell LM. Changes in motoneuron properties and synaptic inputs related to step training after spinal cord transection in rats. J Neurosci. 2007;27(16):4460-71. [PMID:17442831] http://dx.doi.org/10.1523/JNEUROSCI.2302-06.2007

64. Macias M, Nowicka D, Czupryn A, Sulejczak D, Skup M, Skangiel-Kramska J, Czarkowska-Bauch J. Exerciseinduced motor improvement after complete spinal cord transection and its relation to expression of brain-derived neurotrophic factor and presynaptic markers. BMC Neurosci. 2009;10:144. [PMID:19961582] http://dx.doi.org/10.1186/1471-2202-10-144

65. de Leon RD, See PA, Chow CH. Differential effects of low versus high amounts of weight supported treadmill training in spinally transected rats. J Neurotrauma. 2011;28(6): 1021-33.

\section{[PMID:21476782]}

http://dx.doi.org/10.1089/neu.2010.1699

66. Courtine G, Gerasimenko Y, van den Brand R, Yew A, Musienko P, Zhong H, Song B, Ao Y, Ichiyama RM, Lavrov I, Roy RR, Sofroniew MV, Edgerton VR. Transformation of nonfunctional spinal circuits into functional states after the loss of brain input. Nat Neurosci. 2009;12(10): 1333-42. [PMID:19767747] http://dx.doi.org/10.1038/nn.2401

67. Field-Fote EC. Electrical stimulation modifies spinal and cortical neural circuitry. Exerc Sport Sci Rev. 2004;32(4): 155-60. [PMID:15604934] http://dx.doi.org/10.1097/00003677-200410000-00006

68. Singh A, Balasubramanian S, Murray M, Lemay M, Houle J. Role of spared pathways in locomotor recovery after body-weight-supported treadmill training in contused rats. J Neurotrauma. 2011;28(12):2405-16. [PMID:21568686] http://dx.doi.org/10.1089/neu.2010.1660

Submitted for publication June 12, 2012. Accepted in revised form January 8, 2013.

This article and any supplementary material should be cited as follows:

Askari S, Chao T, de Leon RD, Won DS. The effect of timing electrical stimulation to robotic-assisted stepping on neuromuscular activity and associated kinematics. J Rehabil Res Dev. 2013;50(6):875-92. http://dx.doi.org/10.1682/JRRD.2012.06.0111

ResearcherID/ORCID: Deborah S. Won, PhD: H-3001-2013

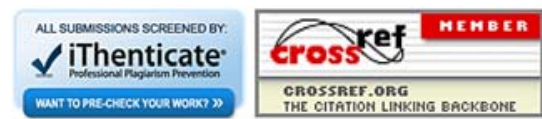

